\title{
A Review of the History and Role of UHMWPE as A Component in Total Joint Replacements
}

\author{
Mrinal K Musib \\ Department of Orthopaedic Surgery and Rehabilitation Medicine, SUNY Downstate Medical Center, Brooklyn, NY 11203, USA
}

\begin{abstract}
Since its introduction as a bearing component for Total Joint Replacements (TJR) by Dr. Charnley in the early 1960's, Ultra-high molecular weight polyethylene (UHMWPE) has become the gold standard to fabricate one of the articulating surfaces of total hip, total knee and total shoulder prostheses. More than a million TJR's are performed every year and is a multi-billion dollar industry. In-spite-of the overwhelming success of this medical procedure, aseptic loosening as a result of wear limits its longevity to 15-20 years. This review article deals with the history of UHMWPE, its material properties that make it an ideal candidate for total joints, implant-component fabrication procedures and provides insights as to why some of the implants eventually fail. Alternate bearing components like $\mathrm{Co}-\mathrm{Cr}$ and $\mathrm{Ti}$ alloys and ceramics are beyond the scope of this review.
\end{abstract}

Keywords TJR, UHMWPE, Wear-Debris, Osteolysis

\section{Introduction}

The advent of UHMWPE as a material to manufacture parts of artificial TJR's started approximately in the year 1962, when Sir John Charnley implanted the first hip prosthesis. Since then it has been the material of choice for the fabrication of one of the articulating surfaces of total joints. Despite the overwhelming success of this restorative procedure, wear of the components and resulting aseptic loosening remains the preemptive problem that limits the lifespan of the these implants from 15-20 years.

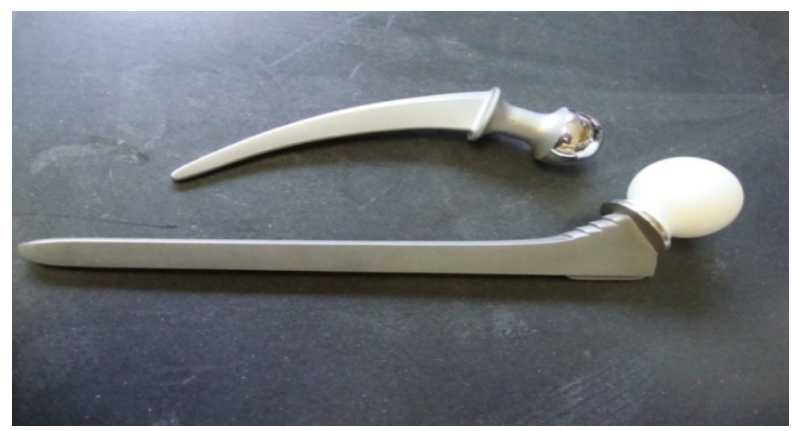

Figure 1. Total hip implant consisting of a metallic stem and head.

A typical hip implant consists of a long metallic stem and a metallic head (usually $\mathrm{Co}-\mathrm{Cr}$ ) (Figure 1) articulating against a UHMWPE polymeric component (Figure 2). As a result of wear at the articulating surface, wear-debris parti-

* Corresponding author:

musib.mrinal@gmail.com (Mrinal Musib)

Published online at http://journal.sapub.org/ijbe

Copyright (C) 2011 Scientific \& Academic Publishing. All Rights Reserved cles (primarily of UHMWPE), varying from a few tens of nanometers to hundred of microns are produced. These particles have been implicated in the wear-mediated osteolytic (aseptic loosening) and eventual failure of the prosthetic device. Figure 3 is a schematic of events showing the sources for the generation of wear-particles and the cascade of events eventually leading to wear-mediated osteolysis. None-the-less recently introduced highly crosslinked UHMWPE remains the material of choice to fabricate implant components, which produces less wear and thus generates less particles.

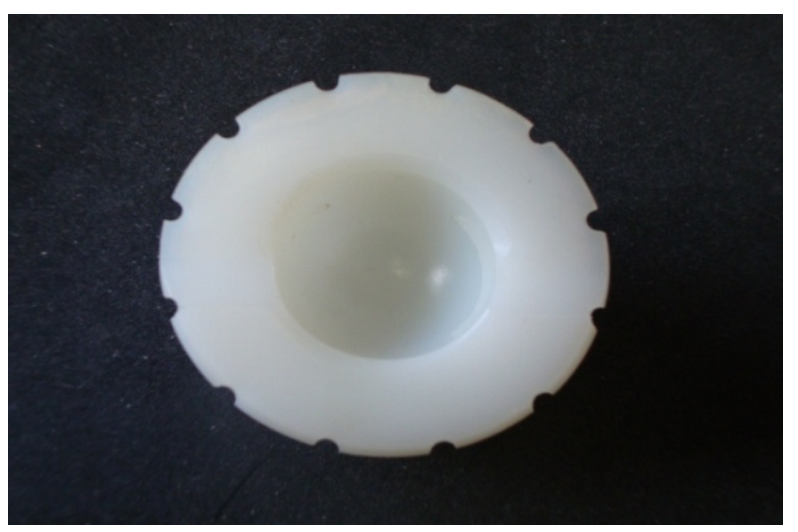

Figure 2. Acetabular cup fabricated from UHMWPE comprises the articulating surface of a total artificial hip.

\section{Fabrication of UHMWPE Components}

UHMWPE is a polymer of ethylene and its molecular chain may contain as-many-as 400,000 carbon units. The 
molecular weight (MW) of UHMWPE is the MW of ethylene multiplied by the number of ethylene groups $\left[\left(\mathrm{CH}_{2}=\mathrm{CH}_{2} \Rightarrow-\left(\mathrm{CH}_{2}-\mathrm{CH}_{2}\right)_{\mathrm{n}}\right]\right.$ and may be between 2 and 6 million grams/per mole.

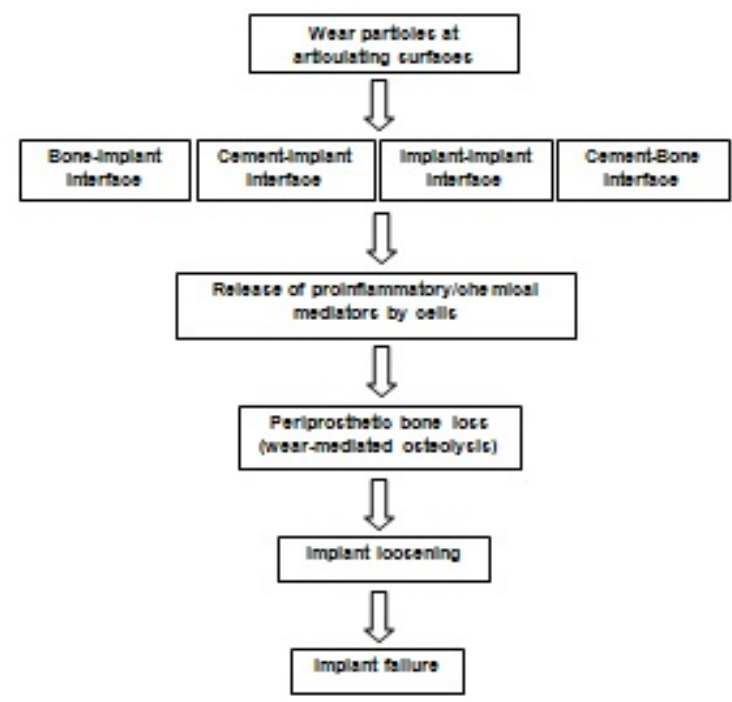

Figure 3. Schematic showing the generation and release of wear debris at the articulating surface and the cascade of events at the periprosthetic region eventually leading to wear-mediated osteolysis and implant failure.

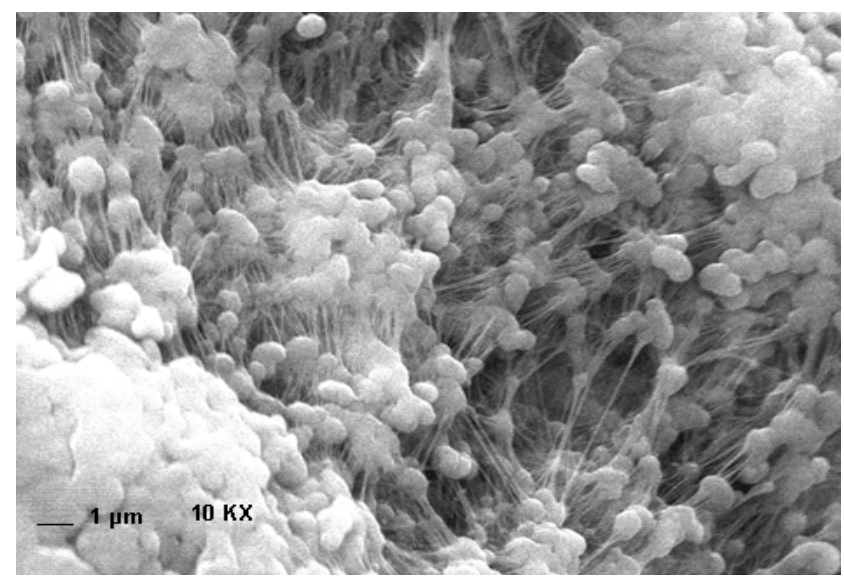

Figure 4. Fibrils (few tens of nanometers in width and few microns in length) connecting individual UHMWPE particles.

UHMWPE is usually produced by Ziegler process involving ethylene, hydrogen and Ti-tetra chloride (catalyst) and is conducted at pressures between 4 and 6 bar at a temp of $66-80{ }^{\circ} \mathrm{C}$. This results in a fine white powder. The molecular chain of UHMWPE can be visualized as an intertwined mass of spaghetti which becomes mobile at higher temperature but at temperature lower than the melting temperature, the chain rotates and folds to form the crystalline region ${ }^{1}$. The degree and orientation of the crystalline regions depends on the molecular mass and the processing and environment conditions. The amorphous regions are embedded within the crystalline structures. These crystalline and amorphous entities of UHMWPE may be visualized using TEM and SEM. When UHMWPE is heated beyond its glass transition temperature, at about $90-100^{\circ} \mathrm{C}$, the amorphous regions become mobile and the crystalline regions begins to melt. The melting point of UHMWPE is about $134^{\circ} \mathrm{C}$. Virgin UHMWPE consists of spheroidal structures $(0.3-2 \mu \mathrm{m})$ joined to each other by fibrils (Figure 4 ) few tens of nanometers thin.

There are several kinds of polyethylene (PE) including low density polyethylene (LDPE), high density polyethylene (HDPE) and UHMWPE. The nomenclature depends on the molecular mass of the material. From a clinical perspective, UHMWPE is more abrasion resistant and wear resistant than either HDPE or LDPE. The toughness is proportional to the molecular mass and as such UHMWPE is tougher than HDPE. Of the many PE's, only UHMWPE is presently used in total joint arthroplasty (TJA).

To be used for medical purposes, the resin powder must meet the requirements as specified in ASTM standard F648 and ISO standard 5834-1. UHMWPE is initially produced as a powder (resin) several tens of microns in size (Figure 5).

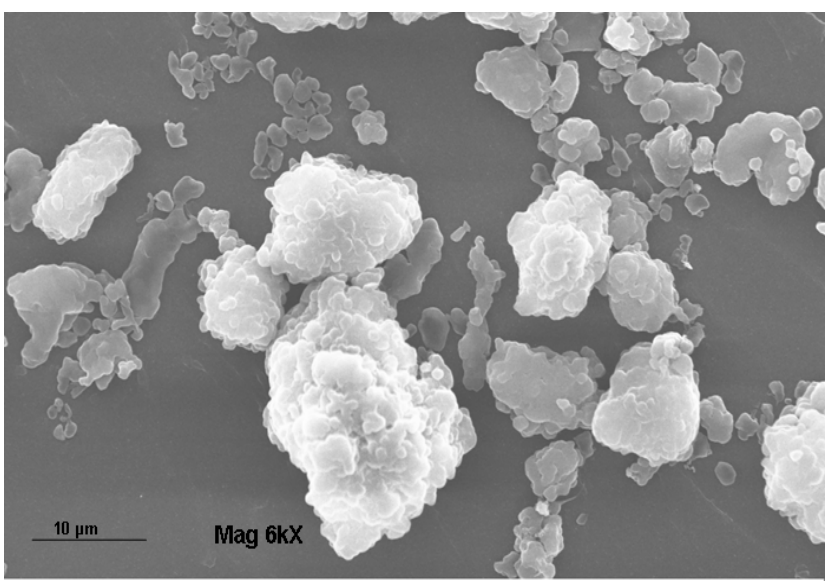

Figure 5. Virgin UHMWPE powder.

The resin is consolidated under high temperature and pressure. Consolidation is the process of fusing the powder into a single, solid piece of material and involves optimization of temperature, pressure and time. It is usually done by either of the following four methods: a) Ram extrusion; b) Compression molding; c) Hot isostatic pressing and d) Direct compression molding. The 'UHMWPE Handbook' by Dr. Kurtz provides comprehensive information pertaining to the fabrication techniques and other relevant details related to UHMWPE.

In ram extrusion, the UHMWPE powder is extruded into a cylindrical bar stock ranging from 2 to 6 inches in diameter. The powder is introduced into a heated cylindrical barrel by a ram and as the ram retracts, the chamber is refilled with UHMWPE powder. Due to the heat and pressure the powder is consolidated into a continuous bar. This method usually includes the addition of Ca-stearate to the raw powder. In compression molding the powder is molded into large sheets. This involves: a) introduction of powder into mold cavity; b) heating of the cavity and c) compression of the plate. Then the sheets are sectioned and turned on a lathe. In direct molding of the implant, the powder is placed in a mold which 
is heated and compressed. The consolidated UHMWPE rods/sheets are further machined into the final implant component. Figure 6 shows the finished product, the fabricated UHMWPE components for hips and knees.

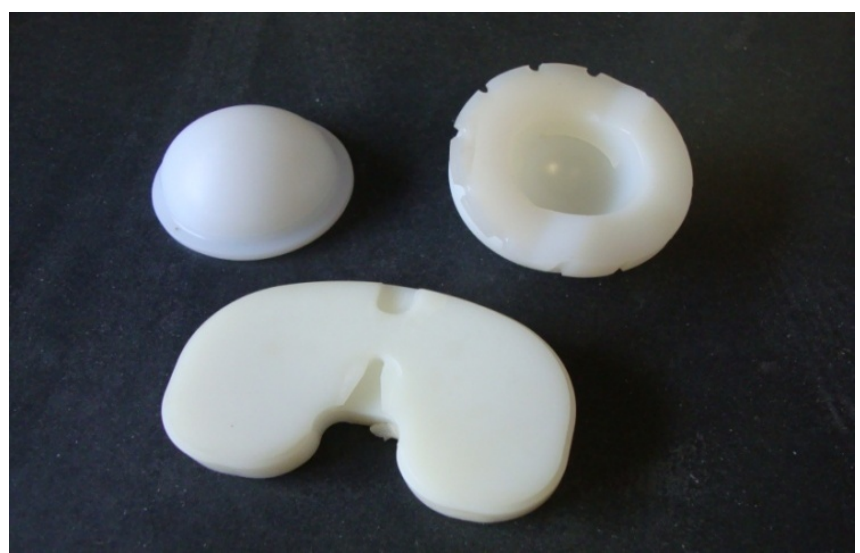

Figure 6. Acetabular and tibial components fabricated of UHMWPE.

Ticona (formerly Ruhrchemie AG, Hoechst) is the largest producer of medical grade UHMWPE. Over 35,000 tons/year of UHMWPE is produced, although $<2 \%$ (700 tons/yr) is premium grade which is used for orthopaedic applications. The main ingredients for producing UHMWPE are ethylene gas, hydrogen and titanium tetrachloride (catalyst). Presently there are 2 different resins produced by Ticona; a) GUR 1020 and b) GUR 1050. Of these two types, GUR 1050 is predominantly being used to fabricate implant components.

GUR stands for 'Granular', 'UHMWPE' and 'Ruhrchemie' respectively. The first digit of the grade name indicates the loose bulk density of the resin. The second digit indicates presence (1) or absence (0) of calcium stearate. Calcium stearate is a scavenger for residual catalyst component and acts as a lubricant and release agent. The third digit relates to the average molecular weight of the resin whereas the fourth digit is a Hoechst internal code designation.

\section{History of PE as an Implant Material}

The concept of total joint arthroplasty came about in the 1950's when Sir John Charnley conducted a series of experiments to study the low coefficient of friction of the natural joint. In 1958, these experiments resulted in the development of low friction arthroplasty with polytetrafluoroethylene (PTFE) as the bearing material. Due to extensive wear and biocompatibility issues Dr. Charnley was looking for a replacement for PTFE. In about 1960, UHMWPE (RCH 1000) was introduced to Dr. Charnley who put it into himself to confirm that it may be a more suitable material for joint articulation than PTFE. In 1962 he used UHMWPE to construct the bearing surface and in 1968 gamma irradiated UHMWPE for the total joints. The following year total joints fabricated using UHMWPE sterilized with 2.5 Mrad were commercially manufactured.
During the early 1970's Zimmer manufactured carbon fiber reinforced UHMWPE and about that time alumina ceramic was used in Japan to fabricate the head of the implant which articulated against UHMWPE. Later during the 1980's the UHMWPE was further modified as a bearing material for total joints and highly crosslinked UHMWPE was introduced in 1999 [ ].

UHMWPE in knee was also introduced in the 1960's and based on the necessity may be uni-, bi-, or tri- compartmental or other designs and thus the design aspects of total knee (TK) is more complex than hip implants. Over 300,000 TK's are performed each year in US alone. Although a successful medical procedure, about $10 \%$ fail after 10 years primarily due to pitting, third body wear, delamination and abrasion. The mechanisms of wear varies with the design aspects of TK components that result in larger contact stresses in the patellofemoral and tibial components compared to the acetabular component and as such TKR are more complex to design and fabricate.

\section{Sterilization and Oxidation Issues}

The components are then sterilized, primarily using any of the three methods: ethylene oxide gas, gas plasma treatment or gamma irradiation. Of these techniques, ethylene Oxide (EtO) and gas plasma are surface sterilization techniques. In ethylene oxide (EtO) usually $100 \% \mathrm{EtO}$ is used. It is a lengthy process of about $40 \mathrm{hr}$ and requires preconditioning/exposure/forced aeration. It usually involves no oxidation or crosslinking. This process may leave toxic residue. In gas plasma technique, Radiofrequency (RF) energy is used to generate plasma from vaporized hydrogen peroxide/paracetic acid. It is expected not to leave any toxic residue. It takes less time, about $4 \mathrm{hr}$ with no lengthy aeration requirements and has no oxidation/crosslinking effects.

The most common method of sterilizing of conventional UHMWPE is gamma sterilization. The gold standard dosage is about $2.5-4 \mathrm{Mrad}$ from a cobalt-60 source ${ }^{2,3}$. The high energy generated during gamma radiation breaks some of the $\mathrm{C}$-bonds in the PE chain and generates free radicals. These free radicals can react in one of three ways: a) Recombination; b) Oxidative Chain Scission and c) Cross-linking. Each of these reactions has different effects on the molecular weight and mechanical properties of the UHMWPE. Chain scission decreases the molecular weight of the polyethylene which in turn results in the degradation of mechanical properties ${ }^{3-7}$. During shelf storage, UHMWPE components that are gamma sterilized in air permeable packaging undergo oxidative degradation, resulting in increase in density and crystallinity and subsequent loss in mechanical properties ${ }^{5,8}$. Some studies have also attributed extensive damage to the mechanical properties to long term shelf ageing ${ }^{9,10}$. Such products become more susceptible to delamination, fracture, decrease in molecular weight, creep deformation and fatigue strength and potential to undergo 
abrasive wear ${ }^{11,12}$. Based on the deleterious effects of oxygen on the longevity of the implant, most manufacturers now-a-days no longer perform gamma irradiation in air. Currently sterilization with gamma irradiation is mostly done in an inert atmosphere. Sterilization of UHMWPE components under vacuum or in an inert oxygen free environment in presence of nitrogen or argon is also widely used. Sterilization in an oxygen free environment decreases oxidation whereas it facilitates recombination and cross-linking that decreases wear of the components in vivo.

To prevent oxidation during radiation sterilization or during shelf life, an antioxidant; vit. E or its synthetic derivative alpha-tocopherol is being used ${ }^{13,14}$. Studies to understand the long term effects of inclusion of such additives to the biomechanical properties and biocompatibility of UHMWPE inserts are presently being conducted.

\section{Crosslinking of UHMWPE}

Presently UHMWPE components are being crosslinked (linking of multiple molecular chains by covalent bonds) by high energy radiation. Although crosslinked UHMWPE may have better wear properties, they may have compromised mechanical characteristics compared to conventional PE. Crosslinking is primarily accomplished by using high energy radiation over $60 \mathrm{kGy}$ and then annealing just below or above the melting point of UHMWPE (about $135^{\circ} \mathrm{C}$ ) to quench the free radicals ${ }^{3}$. Crosslinking improves the wear characteristics and as such less number and volume of wear particles are generated which has been implicated in wear-mediated osteolysis. This has improved biocompatibility of crosslinked UHMWPE inserts.

Crosslinking also decreases the number of wear debris that are generated at the articulating surfaces. As these debris have been implicated in osteolysis ${ }^{15-18}$, generation of less debris may theoretically increase the longevity of implant components. Studies have been conducted to isolate, fractionate and characterize these debris ${ }^{19}$. Previously chemical and enzymatic techniques have been used to isolate wear debris particles ${ }^{20,21}$. The results may help us better understand the phenomenon of wear-mediated osteolysis.

\section{Conclusions}

Since its introduction into the field of orthopedics by Dr. Charnley over 50 years ago, UHMWPE is still the gold standard as an articulating surface for total joints. Oxidation as a result of high energy radiation and extended shelf life may cause wear-mediated osteolysis has been attributed to long term failure of total prostheses. Although much work still needs to be done to understand the underlying mechanism of its pathogenesis, it is generally accepted that periprosthetic bone resorption is initiated by an aseptic inflammation to wear debris generated from continuous wear, abrasion, or corrosion of implant components at the articulating surface. If left untreated, progressive osteolysis caused by wear particles can result in substantial bone loss and subsequent implant failure. To prevent oxidation and improve wear properties, UHMWPE components are being crosslinked and additives (antioxidant as Vit E. or its synthetic derivatives) are being included. This will help manufacturers to enhance the longevity of such inserts and thus prevent their premature failure.

\section{REFERENCES}

[1] Turell MB, Bellare A. A study of the nanostructure and tensile properties of ultra-high molecular weight polyethylene. Biomaterials 2004;25 (17) :3389-98

[2] Costa L, Jacobson K, Bracco P, Brach del Prever EM. Oxidation of orthopaedic UHMWPE. Biomaterials 2002; 23(7):1613-24

[3] Brach Del Prever EM, Bistolfi A, Bracco P, Costa L. UHMWPE for arthroplasty: past or future? J Orthop Traumatol 2009;10(1):1-8

[4] Kurtz SM, Muratoglu OK, Evans M, Edidin AA. Advances in the processing, sterilization, and crosslinking of ultra-high molecular weight polyethylene for total joint arthroplasty. Biomaterials 1999;20(18):1659-1688

[5] Kurtz SM, Hozack W, Marcolongo M, Turner J, Rimnac C, Edidin A. Degradation of mechanical properties of UHMWPE acetabular liners following long-term implantation. J Arthrop 2003;18(7 Suppl 1):68-78

[6] Besong AA, Tipper JL, Ingham E, Stone MH, Wroblewski BM, Fisher J. Quantitative comparison of wear debris from UHMWPE that has and has not been sterilised by gamma irradiation. J Bone and Jt. Surg.Br 1998;80(2):340-344

[7] McKellop H, Shen FW, Lu B, Campbell P, Salovey R. Effect of sterilization method and other modifications on the wear resistance of acetabular cups made of ultra-high molecular weight polyethylene. A hip-simulator study. J Bone and Jt. Surg.Am 2000;82-A(12):1708-1725

[8] Blunn G, Brach del Preva EM, Costa L, Fisher J, Freeman MA. Ultra high molecular-weight polyethylene (UHMWPE) in total knee replacement: fabrication, sterilisation and wear. J Bone Joint Surg Br 2002;84(7):946-9

[9] Costa L, Luda MP, Trossarelli L, Brach del Prever EM, Crova M, Gallinaro P. Oxidation in orthopaedic UHMWPE sterilized by gamma-radiation and ethylene oxide. Biomaterials 1998;19(7-9):659-68

[10] Besong AA, Hailey JL, Ingham E, Stone M, Wroblewski BM, Fisher J. A study of the combined effects of shelf ageing following irradiation in air and counterface roughness on the wear of UHMWPE. Bio-medical Mater. and Engg. 1997;7(1):59-65

[11] McKellop HA. The lexicon of polyethylene wear in artificial joints. Biomaterials 2007; 28 (34) :5049-5057

[12] Kurtz SM, Rimnac CM, Pruitt L, Jewett CW, Goldberg V, 
Edidin AA. The relationship between the clinical performance and large deformation mechanical behavior of retrieved UHMWPE tibial inserts. Biomaterials 2000;21(3):283-291

[13] Oral E, Wannomae KK, Rowell SL, Muratoglu OK. Diffusion of vitamin E in ultra-high molecular weight polyethylene. Biomaterials 2007;28 (35):5225-5237

[14] Oral E, Muratoglu OK. Vitamin E diffused, highly crosslinked UHMWPE: a review. Int Orthop 2011;35(2):215-23

[15] Campbell P, Shen FW, McKellop H. Biologic and tribologic considerations of alternative bearing surfaces. Clin. Orthop and Rel Res 2004;(418)(418):98-111

[16] Jacobs JJ, Campbell PA, T Konttinen Y, Implant Wear Symposium Biologic Work G. How has the biologic reaction to wear particles changed with newer bearing surfaces? J Am Acad of Orthop Surg 2008;16(1):49-55

[17] Fisher J, McEwen HM, Tipper JL, Galvin AL, Ingram J, Kamali A, Stone MH, Ingham E. Wear, debris, and biologic activity of cross-linked polyethylene in the knee: benefits and potential concerns. Clin Orthop and Rel Res 2004;(428)(428):114-119

[18] Goodman SB, Fornasier VL, Lee J, Kei J. The histological effects of the implantation of different sizes of polyethylene particles in the rabbit tibia. J Biomed Mater Res 1990;24(4):517-524

[19] Saha S, Musib M. Fractionation and Characterization of Particles Simulating Wear of Total Joint Replacement (TJR) Following ASTM Standards. J Long Term Eff Med Implants 2011;21(1):79-92

[20] Campbell P, Doorn P, Dorey F, Amstutz HC. Wear and morphology of ultra-high molecular weight polyethylene wear particles from total hip replacements. Proc Institution of Mech Engineers.Part H, J of Engg in Med 1996;210(3):167-174

[21] Affatato S, Emiliani D, Bersaglia G, Traina F, Toni A. An easy technique to digest and isolate UHMWPE wear particles from a hip joint simulator. Int $\mathrm{J}$ Art Organs 2004;27(5):424-432 